TEMPUS Revista en Historia General Medellín (Colombia), 2017, Segundo Semestre, Número 6 Pp. 174-193, ISSN: 2422-2178 (En línea)

\title{
APROXIMACIÓN AL PANARABISMO: UNA IDEA INMANENTE EN EL PENSAMIENTO DE LAS GENTES O UN FENÓMENO DE COYUNTURA.
} AUGE Y DECLIVE. 1955-1967

Gerson Stiven Mosquera Cetre ${ }^{1}$

Universidad de Antioquia.

DOI: 10.17533/udea.tempus.n6a07

\section{Resumen}

Es indudable que la aparición del Estado de Israel marca un punto de inflexión en el mapa político del Oriente próximo, marcando una serie de comportamientos, adhesiones y disensiones entre las naciones árabes existentes, provocando dentro de la constitución y desarrollo de las mismas, múltiples procesos de reflexión que se veían inmersos en el diseño de sus proyectos nacionales, actuaciones políticas y diplomáticas, siendo el desarrollo de la Guerra Fría, la cuestión palestina y la búsqueda de justicia social y de un aumento generalizado de la calidad de vida, las principales cuestiones. Este artículo analiza de forma generalizada las relaciones diplomáticas de las recientes naciones árabes en pro de la consecución de respaldo económico y político-militar frente a la existencia del Estado de Israel, siendo Egipto, Siria e Iraq, los conductores del Panarabismo como proyecto político mancomunado que buscaba la adherencia de los países árabes en pro de la solución de los problemas políticos y militares comunes, sin embargo la cristalización de la relaciones diplomáticas flexibles y variables, tanto dentro del ámbito regional, como internacional de alguna forma truncaron y obstaculizaron su crecimiento, por la misma variabilidad y el carácter ambiguo de sus premisas, proyectos y fines políticos.

Palabras Claves: Nasser, Oriente Próximo, Egipto, Siria, Panarabismo, Israel.

\section{Abstract}

It is undoubted that Israel's appearance marks an inflection point in the political map of the Next East, marking a series of behaviors, adherences and disagreements between the existing Arab nations, provoking inside the constitution and development of multiple processes of reflection that were turning out to be immersed in the design of its national

\footnotetext{
${ }^{1}$ Estudiante de historia, Universidad de Antioquia. Gerson.mosquera@udea.edu.co
} 
projects, political and diplomatic performances, being the development of the Cold War, the Palestinian question and the search of social justice and of a widespread increase of the quality of life, the main questions. This article analyzes of widespread form the diplomatic relations of the recent Arab nations to the advantage of the attainment of economic support and politician-military man opposite to the existence of the State of Israel, being Egypt, Syria and Iraq, the drivers of the Panarabism as joint political project that was looking for the adhesion of the Arab countries to the advantage of the solution of the common political and military problems, nevertheless the crystallization of the flexible and variable diplomatic relations, so much inside the regional ambience, as international of some form they truncated and hindered its growth, for the same changeability and the ambiguous character of its premises, projects and political ends

Keywords: Near East, Pan-arabism, Egypt, Nasser, Israel, Syria.

\section{Introducción.}

El conflicto árabe-israelí ha sido si se quiere uno de los conflictos más álgidos e intrincados durante el siglo XX, a su vez ha generado múltiples adhesiones y posiciones, respecto a sus dinámicas y ejes beligerantes, mucho más teniendo en cuenta la posición del Estado de Israel dentro del mapa político-militar del Oriente próximo. En ese sentido la aparición del panarabismo en los años 60's, marcó la comunión de intereses de las distintas naciones árabes bajo la égida de un pensamiento integrista respecto a las necesidades, problemas, ambiciones y discusiones con relación a la protección de la soberanía de cada uno de los estados del mundo árabe, respecto de los intereses económicos de las potencias occidentales, el afán expansionista del Estado de Israel, la solución de la problemática palestina y de las distintas dificultades socio-económicas de estas naciones.

Hay que tener en cuenta que la coyuntura de los 50's y 60's marcaba una etapa de ascenso económico, modernización y tecnificación de los procesos productivos. Dentro de ésta dinámica el ejercicio económico y comercial del primer mundo de la época, dependía de forma casi exclusiva de las reservas petrolíferas del Oriente Próximo, lo que hacía a ésta región indispensable dentro del mapa político y diplomático de las potencias de la época, más cuando había una disputa abierta por la supremacía en el globo terráqueo, en el marco de la Guerra Fría. Puesta así la situación, los informes económicos de los diplomáticos estadounidenses en el Magreb señalaban que "los descubrimientos en 
Argelia y Libia, en relación a los países de Europa Occidental reducirán la relación de dependencia hacia el Cercano Oriente e Irán, las estimaciones actuales indican que en 1965 el área seguirá siendo el suministro de Europa Occidental con el grueso de sus necesidades de petróleo. El efecto de los descubrimientos de África del Norte es reducir la dependencia de Europa Occidental en relación a la zona, no para eliminarla. En las circunstancias actuales, no hay a la vista ningún sustituto adecuado para reemplazar enteramente las vastas reservas de petróleo de la zona"2.

Teniendo en cuenta la aseveración anterior nadie puede discutir la primacía de los factores económicos, en la toma de decisiones políticas. En esa perspectiva, el Oriente próximo durante su proceso de descolonización, no fue la excepción, y más, teniendo en cuenta las muy diversas características políticas, sociales y culturales de la región y la preponderancia de ciertos factores de calado religioso, político y cultural en la configuración ideológica de la vida, el territorio, la tierra etc.

\section{El panarabismo como proceso de postura política frente a los afanes económicos de las potencias occidentales.}

Lo cierto es que al analizar la formación y construcción de las repúblicas árabes a partir de 1950, encontramos una problemática bastante particular que hizo de la reivindicación de los derechos y necesidades de las clases obreras y agrícolas una constante, independientemente de las relaciones de élite construidas durante la primera mitad del siglo XX, así mismo, la preeminencia del islam en términos religiosos, paso a un segundo plano, lo que de alguna forma le dio validez y legitimidad a la constitución de múltiples formaciones político-administrativas de características laicas y militares, en esas perspectivas, esas formaciones políticas se vieron influidas teórica e intelectualmente, por distintas tendencias ideológicas, todas en contra de los intereses imperialistas tanto sionistas.

Teniendo en cuenta la problemática socio-económica del mundo árabe, fue más que predecible la constitución del Panarabismo, como proceso ideológico reparador y reformador de las dificultades no sólo socio-económicas, sino también políticas y culturales del mundo árabe, aspirando a cohesionar un pensamiento alrededor de la idea

2 Department of State, S/S-NSC Files: Lot 63 D 351, NSC 6011. Top Secret. 0297. http://nasser.bibalex.org/Data/USDocWeb/PDF/Near-East-Region-58-60-XII/TXT/Near-East-Region-5860-XII\%20-\%200297.pdf 
de ser, pertenecer y vivir como árabe, utilizando múltiples organismos multilaterales, para de alguna forma empoderarse de sus territorios, espacios y decisiones.

Hay que tener en cuenta que el Panarabismo, surgió de la construcción ideológica, alrededor del socialismo árabe, en esa perspectiva hay que aclarar que este nació bajo el seno de la producción intelectual de distintos personajes pertenecientes a las élites sirias, en su mayoría del sector comerciante de éstas, que debido a su instrucción y educación en las universidades europeas, comienzan a tener una visión muy distinta de las realidades socio-económicas, no sólo del ámbito sirio, sino también del Oriente Próximo en general.

Marcada de alguna manera por el aporte de intelectuales de distintas minorías religiosas, en el caso de Michel Aflaq, quizá el más brillante teórico del socialismo árabe, resalta cómo su proceso de formación en la Sorbona cohesionó una visión más integral de la problemática árabe, destacando que "antes de llegar a Francia, tenía un sentimiento nacionalista árabe; En especial estaba influenciado por mi padre y había respondido con pasión a las injusticias padecidas por la nación árabe. El nacionalismo fue nuestra realidad local, pero en París estaba en contacto con otras teorías, descubrí otras perspectivas, me llevó a preguntarme más... Me forjé la idea de una nueva sociedad, abierta al mundo moderno ... finalmente proyectados de manera que el nacionalismo no podría ser sólo un grito del corazón, un reclamo legítimo, pero mal redactado y que en su lugar debería basarse en bases sólidas y considerar todos los campos: político, cultural, social y económico." ${ }^{3}$ Imprimiéndole, cierto sentido comunitario a la solución de la cuestión social, que ni la idiosincrasia árabe ni la fe islámica poseen.

Pero dentro del proceso de constitución del Panarabismo hay dos factores fundamentales que lo hicieron posible y que le dieron las características tan particulares que posee, siendo los puntales del proceso histórico que dio con la constitución de las repúblicas árabes y la transformación y modernización de sus instituciones, principalmente las militares.

El primero es el proceso de descolonización que hubo en la región, después de la Segunda Guerra Mundial y lo que representa éste en relación al nuevo orden mundial que

\footnotetext{
${ }^{3}$ Louise Plun, «Michel Aflaq et Salah al-Bitar: idéologues et fondateurs du parti Ba'th» Fecha de consulta: 9 de octubre, 2015, http://www.lesclesdumoyenorient.com/Michel-Aflaq-et-Salah-al-Bitar.html\#nh7 Tomado de: Charles Saint-prot, "Le Mouvement National Arabe, Emergence et Maturation Du Nationalisme Arabe de La Nahda Au Baas," Ellipses, 2013.
} 
representa la pérdida de poder y legitimidad de los aparatos políticos-administrativos de las principales potencias colonizadoras de la época, Gran Bretaña y Francia, frente a las élites locales de la zona. Y también la preeminencia de las misiones diplomáticas, las instituciones privadas y empresariales en la captación, negociación y extracción de los recursos económicos de la región, dinámica dentro de la cual los Estados Unidos iba a marcar una muy importante influencia a partir de los años 50's.

Esta situación provocó la revaluación de los vínculos políticos y financieros de las potencias que perdían poder e influencia dentro de la región, así como las que cada vez tenían más poder dentro de la misma con los distintos gobiernos de la zona. Así mismo surge la iniciativa de reafirmar, proteger y conservar el acceso a los recursos energéticos y petrolíferos del Oriente Próximo, asegurando también la circulación y transporte de estos.

Lo que marca a su vez las dos caras de la moneda, por un lado el descenso económico, militar y político de Gran Bretaña y Francia, las huellas de dos guerras mundiales, teniendo como única consecuencia, la preeminencia de las cuestiones internas e intentos desesperados por conservar por la fuerza sus regímenes coloniales. Y por el otro el ascendente económico de los Estados Unidos, sus amplias conexiones diplomáticas, sustentadas en el papel de las instituciones privadas y financieras, que a su vez estaban detrás de la modernización y tecnificación de las distintas actividades económicas de la época, que en amplia variedad de casos eran más que necesarias para el aprovechamiento y extracción de recursos naturales en distintas zonas del mundo, y el Próximo Oriente no era la excepción. En estas condiciones la asesoría y asistencia económica en las repúblicas árabes era indispensable, fue así como la diplomacia norteamericana y soviética se dieron a la tarea de ganar influencia en una zona donde no había un claro poseedor y beneficiario de los recursos.

El segundo factor para entender la aparición del Panarabismo es el infortunio militar que representa la guerra de independencia israelí en 1948, donde un ejército menor en número y recursos, usó de forma magistral las características topográficas de Palestina, para vencer a una coalición de ejércitos árabes, descoordinados en objetivos y causa, como también en batalla, debido al panorama variopinto de intereses de los distintas élites conductoras de las repúblicas árabes en relación a la existencia del Estado de Israel, como 
la influencia de los funcionarios ingleses y franceses en la toma de decisiones de estos gobiernos, que en muchos casos estaban sustentados en el derecho de sangre.

En términos políticos, la situación de los estados postcoloniales, cambió debido a la ruptura que es protagonizada en primera instancia por dos regímenes, que ascendieron gracias a acciones militares en contra del poder establecido, uno en Egipto, protagonizado por la revolución de los oficiales libres y que terminó encontrando en Gamal Abdel Nasser, su líder político en 1952, y otro en Siria, protagonizado por un movimiento de unidad nacional, que terminó con la preeminencia en el poder de Khaled Bagdach en 1956.

El triunfo de estas transformaciones políticas estuvo en la capacidad política de estas en aunar los intereses de las masas, alrededor de sus proyectos políticos y sostenerlos a partir de un incipiente poder militar, enmarcado en un ámbito de creciente modernización y a partir de esas perspectivas abogar dentro de espacios multilaterales creados por la potencias en el cuidado de sus intereses económicos, por el rescate e integración de la cultura árabe, a través de sus elementos y problemáticas, así, sin más, de forma casi espontanea, fue como se empezó a gestar un idea política, que si bien no tenía muy bien proyectados sus fines políticos, pudo ser núcleo por primera vez en mucho tiempo de la proyección y ejecución de múltiples acciones políticas y económicas dentro de un marco teórico coherente, eso sí, planteado a corto plazo, procurando la prevalencia de los intereses de las distintas clases sociales. En ese orden ideas, el objetivo de este artículo es dilucidar el carácter efímero de esta dinámica, analizando los fenómenos coyunturales que le dieron vida, como los que contribuyeron a su desaparición.

\section{La dependencia económica.}

Cuando se habla del despertar del mundo árabe, hay que hablar de los múltiples desaciertos de las potencias occidentales, en torno a la formación de los estados postcoloniales en la región, respondiendo a la lógica de la distribución de los recursos naturales más productivos, entre ellas, para ponerlos a su permanente disposición y servicio.

En ese sentido la organización política y social de los estados postcoloniales, nunca fue un asunto preponderante en la agenda de las potencias, teniendo en cuenta la falta de legitimidad que siempre tuvieron las élites instauradas en el poder de estos estados. Teniendo en cuenta esta perspectiva, en términos económicos podemos ubicar 
para finales de la década de los 40's y para el comienzo de los años 50's, estados donde la distribución de la tierra era supremamente desigual, la producción ineficaz, la pobreza una regla y la modernización como la modernidad tareas pendientes, lo que de alguna forma denota la situación de las clases obreras y agrícolas.

Por ejemplo en el ámbito egipcio "las clases medias de la ciudad y el campo son importantes. Sin embargo, más de la mitad de la población egipcia está constituida por campesinos sin tierra y sus familias que apenas pueden emplearse en un tercio de su capacidad de trabajo. La clase obrera suma dos millones de trabajadores, más de la mitad de los cuales son obreros agrícolas", Siria "recién hacia 1950 comienza una nueva etapa de la industrialización. Pero sólo se trata de la industria de transformación. Y su peso sigue siendo débil en la renta nacional, alrededor del 10\%. Emplea 100.000 obreros sobre una población de 3.800.000 habitantes" 5 , mientras tanto para "1958, el 80\% de los iraqueses vivía aun de la agricultura. En el campo predomina(ban) las relaciones feudales. Los grandes terratenientes poseen el $60 \%$ de las tierras, y 272 de entre ellos poseen el $45 \% " 6$.

Por tales motivos es más que pertinente entender la filiación que empieza a desarrollar los sectores intelectuales y progresistas árabes respecto a la solución de las problemáticas socio-económicas en tendencias ideológicas como el marxismo-leninismo y el socialismo, buscando adaptarlos a las formas y necesidades propias de las sociedades y contextos árabes, tratando de otro lado de combatir el predominio económico francés y británico en la región.

Para la consecución de tal fin, fue más que necesaria la presencia de hombres fuertes, de instrucción castrense, en la tarea de darle y ponerle orden a la distribución de los recursos públicos y financieros, ampliando de alguna forma el espectro político y garantizando la participación de las masas dentro del ejercicio político, para ganarse su legitima aceptación. Lo que de alguna forma se denota en este relato de un diplomático español, sobre las reformas sociales que protagonizó Nasser dentro del ámbito egipcio: "En Asswan tuve la ocasión de visitar la gran fábrica de fertilizantes que ha acabado con el añejo tópico de los "limos del Nilo". Se trata de un complejo fabril grandioso, dotado de las más modernas técnicas empleadas en la fabricación de abonos y en la que ha sido

\footnotetext{
${ }^{4}$ Jacques Couland, El Despertar Del Mundo Árabe (Buenos Aires: Arandú, 1965), 78.

${ }^{5}$ Couland, El Despertar Del Mundo Árabe, 86.

${ }^{6}$ Couland, El Despertar Del Mundo Árabe, 92.
} 
cuidada también, de manera admirable, la dignidad de los miles de trabajadores allí empleados. Junto a magnificas viviendas, disponen de comedores en los que yo les vi tomar el almuerzo de mediodía por el módico precio de dos piastras, equivalente a unas dos pesetas. (...) Probablemente Egipto, hoy, es el país más barato del mundo en artículos de primera necesidad ${ }^{7}$.

Aunque es indiscutible la importancia del caudal económico de las potencias, representado en el funcionamiento de las instituciones financieras, la inversión y la importación de productos manufacturados, para dinamizar los pocos sectores económicos rentables, de unas economías en su gran mayoría mono-exportadoras con relación a las materias primas relacionadas principalmente con el sector petrolífero y energético.

Con el estallido en la década de 1950 de los primeros reductos del nacionalismo árabe, lo que se hizo más evidente fue la poca productividad de estas economías y la necesidad de reestructurar sus vínculos y sistemas económicos, así "Egipto a principios de 1952, es el país árabe más industrializado. En circunstancias favorables de la segunda guerra mundial, su producción industrial aumentó en un tercio de su valor, pero era todavía dos veces y media inferior al valor de la producción agrícola. ${ }^{8}$

Teniendo en cuenta esto hay que resaltar que la Revolución de los oficiales libres en 1952, marcó el camino de la consecución de las reformas políticas dentro del ámbito egipcio centrándose en la disolución de los partidos políticos y la consolidación de un ideal nacionalista y unificador, en detrimento del dominio británico, que se quedó sin representantes debido a que fueron desplazados del mapa político por los funcionarios nasseristas, quienes por medio de su líder, tenían para 1954 pactada la salida de las tropas británicas del ámbito egipcio.

En términos sociales, ante la incipiente desigualdad en la tenencia de la tierra, se realizó una reforma agraria para 1952, que sólo sería productiva en la medida que se diera la modernización del campo egipcio, por medio de la construcción de la presa de Asuán, vital para el crecimiento agrícola del país. Para lo cual era más que indispensable asistencia técnica y económica.

\footnotetext{
${ }^{7}$ Pascual Marín Pérez, Lo Que vi En La R.A.U (Madrid: Embajada de la República Árabe Unida, 1966), 95.

${ }^{8}$ Couland, El Despertar Del Mundo Árabe, 77.
} 
De ahí la importancia de las alianzas políticas y la participación dentro del juego político de la Guerra Fría, así "para financiar la Gran Presa (de Asuán), el Gobierno de la República Árabe Unida acudió a los Estados Unidos, a Gran Bretaña y al Banco Mundial de Construcción y desarrollo, que aceptaron participar en la financiación del proyecto. Pero el 19 de julio de 1956, los Estados Unidos, seguidos de Gran Bretaña y de la Banca Internacional, retiraron, inesperadamente su oferta de ayuda, cuando el gobierno de la República Árabe Unida había comenzado ya la ejecución de la obra. Una semana más tarde, el 26 de julio, el presidente Nasser anunciaba la nacionalización de la compañía del Canal de Suez, puesto que las divisas extranjeras recaudadas debían servir para la realización del proyecto ${ }^{9}$

La ruptura que marcan las actuaciones y las decisiones de Nasser, frente al accionar de las potencias occidentales, lo convirtió en uno de los más interesantes e incipientes objetivos de la Unión Soviética, dentro de la perspectiva del Oriente Próximo principalmente porque había establecido a los deseos e intereses de las potencias occidentales y se había convertido junto con los sirios, en los principales precursores del antimperialismo, el panarabismo y la resistencia a la consolidación del Estado de Israel, pero de forma activa, práctica y efectiva, mostrando que la unión de las republicas árabes podrían fundar real oposición a las perspectivas de los sectores públicos y privados de las potencias, fundados en las corporaciones industriales y financieras enfocadas principalmente en el sector energético y petrolífero.

Lo que marca de alguna forma, la necesidad de asegurarse recursos en materia militar, necesarios para mantener la estabilidad y la legitimidad en relación a las cuestiones internas, tanto como para modernizar e industrializar ámbitos productivos con amplia participación agrícola.

Otro aspecto de suma importancia fue la construcción de las relaciones regionales, partiendo de la premisa de la cooperación y el fortalecimiento económico de lazos entre las naciones árabes, en términos políticos, económicos y culturales, con el fin de difundir y diseminar la concepción nacionalista árabe, tratando de consolidar un bloque político fortificado frente a la acción y la influencia tanto de las potencias occidentales como del Estado de Israel, de ahí partió la necesidad de estructurar una vida política y diplomática alterna a las disputas propias de la Guerra Fría, todo en respuesta a los logros del Nasser

\footnotetext{
${ }^{9}$ Marín Pérez, Lo Que vi En La R.A.U, 94.
} 
en Egipto, la presencia de los ideales nasseristas a lo largo y ancho del mundo árabe y la radicalización política de corte socialista y comunista que sufrieron Siria e Iraq.

Pero sin duda fue la Conferencia de los países no alineados en 1956, la que consolidó el camino y el avance de las ideologías alternativas a las posiciones de las potencias, promoviendo la consolidación de las perspectivas económicas y políticas de países del tercer y cuarto mundo, muchos de ellos recién fundados, para los cuales, el papel de sistemas políticos de comprobada viabilidad, sustento y supervivencia como el cubano y el egipcio marcaron la pauta, llamando principalmente al real derecho a la autodeterminación, reivindicándose el siguiente año precisamente en una "reunión en El Cairo de la Confederación de afro-asiática que reafirma, a fines del año 1957, los principios de Bandung y pone el acento sobre la cooperación económica y cultural, permitirá al movimiento democrático desarrollarse más aun en las masas.”10

Los países más consecuentes en su política anti imperialista y neutralista se fusionaran en la República Árabe Unida ${ }^{11}$, que terminó siendo un intento frustrado por cohesionar una entidad panárabe funcional respecto a unas prerrogativas políticas, jurídicas y administrativas, aspirando a la autonomía cultural, económica y social de cada espacio geográfico, relación en la cual "Kamal Al-Jaderji, líder del Partido Nacional Democrático emprende conversaciones con Egipto para definir una forma de unidad entre ambos países. Las gestiones fracasan, ya que los iraqueses no logran hacer prevalecer una forma federativa; la existencia de los partidos en Iraq y la imposibilidad de llegar a un acuerdo sobre la cuestión del mando del ejército, alejan la de una solución semejante a la de Siria"12 en esa misma línea de argumentos también se percibe como "la reforma agraria es frenada en su desarrollo y las cooperativas aseguran la preponderancia económica de los propietarios más ricos. Siria se convierte cada vez más en un apéndice agrícola de Egipto, que exporta allí sus productos industriales y sus capitales. Se agudizan las contradicciones entre ambos países"13.

\section{El carácter militar de los gobiernos panarabistas.}

Las disputas político-militares entorno a la cuestión palestina y respecto de otros enclaves de las potencias occidentales en la región representaron para los estados

\footnotetext{
${ }^{10}$ Couland, El Despertar Del Mundo Árabe, 84.

${ }^{11}$ Couland, El Despertar Del Mundo Árabe, 84.

${ }^{12}$ Couland, El Despertar Del Mundo Árabe, 95.

${ }^{13}$ Couland, El Despertar Del Mundo Árabe, 99.
} 
panárabes la principal dificultad y una de las principales causas de su posterior disolución, en ese sentido, la guerra del Sinaí y la guerra de los Seis Días, fueron demostraciones fehacientes de la preeminencia militar y económica del Estado de Israel, frente a las iniciativas militares de repúblicas árabes patrocinadas en gran medida por la Unión Soviética y con cierto ascendente económico, pero nunca respaldadas por una tradición militar, técnica y estratégica medianamente equiparable al proyecto y las necesidades Estado de Israel.

Sin embargo las "victorias" diplomáticas de Nasser y su preponderancia dentro la política exterior y la diplomacia dentro de la región, frente a las pretensiones territoriales del Estado de Israel respecto del Sinaí, luego de la guerra de 1956, hicieron pensar de alguna forma que el bloque panárabe había ganado cierta estabilidad política como económica para enfrentar y prevalecer ante el poderío económico del Estado de Israel en la región.

Teniendo en cuenta "las intenciones soviéticas en el Cercano Oriente. Un aumento en el poder soviético en el Cercano Oriente, hasta el punto donde los intereses especiales en líneas de comunicación e instalaciones estratégicas podrían ser negados a Occidente sería un importante revés para los intereses de Estados Unidos" ${ }^{14}$ sin importar que "el nacionalismo árabe, como tal, es fundamentalmente incompatible con los objetivos comunistas, aunque muchos de sus objetivos a corto plazo han sido y todavía son coincidentes con las de la Unión Soviética"15, de ahí el principal interés de la diplomacia norteamericana respecto a las posiciones de liderazgo tomadas por Nasser dentro de la región, ya que se convirtió en un factor determinante en el preservación del equilibrio regional y en la principal opositor a la seguridad del Estado de Israel, tomando en consideración la influencia soviética en su modernización militar.

Ya que para 1956, el eje Sirio-egipcio habría cobrado mayor protagonismo en la región, además de haberse hecho con el prestigio de las demás naciones árabes, estaba fuera del dominio inglés y francés, y en el caso egipcio se había vuelto padrino de las distintas causas independentistas del mundo árabe, participando activamente en la que

14 Department of State, S/S-NSC Files: Lot 63 D 351, NSC 6011. Top Secret. 0296. http://nasser.bibalex.org/Data/USDocWeb/PDF/Near-East-Region-58-60-XII/TXT/Near-East-Region-5860-XII\%20-\%200296.pdf

15 Department of State, S/S-NSC Files: Lot 63 D 351, NSC 6011. Top Secret. 0295. http://nasser.bibalex.org/Data/USDocWeb/PDF/Near-East-Region-58-60-XII/TXT/Near-East-Region-5860-XII\%20-\%200295.pdf 
sostenían argelinos contra franceses y yemeníes contra ingleses, a eso se podría sumar las perspectiva de nacionalizar el canal de Suez y el fracaso del plan de paz Alfa para la guerra de independencia israelí de 1948, que para 1956 se había convertido en una carrera armamentística enfocada en la producción nuclear entre el eje sirio-egipcio y el Estado de Israel, el primero secundado por la Unión Soviética y el segundo ayudado por Francia.

Esta amplia cantidad de factores, condesaron la Crisis del canal de Suez, siendo "una conflagración internacional de cuatro meses durante la cual Gran Bretaña y Francia concentraron poco a poco sus tropas en la región y advirtieron a Nasser de que estaban dispuestos a utilizar la fuerza militar para restablecer su titularidad de la compañía del canal a menos que él cediera. Las autoridades británicas y francesas esperaban secretamente que la presión ocasionaría finalmente la caída de Nasser del poder, con o sin una acción militar de su parte" $"$.

Pero fue una maniobra fallida, teniendo en cuenta, que los Estados Unidos temiendo una penetración de las perspectivas soviéticas en la región y un levantamiento masivo de los gobiernos y movimientos políticos del mundo árabe, prefirió respaldar los intereses egipcios, de paso deslegitimando la acción e influencia de tanto franceses como ingleses de forma definitiva en la región y haciendo optar a Israel por una política tendente al equilibrio armamentístico y diplomático del Oriente Próximo, Así mismo se ganó el derecho de tender asistencia técnica y económica al gobierno egipcio.

Dentro de este juego de poderes, las acciones que cada uno de los bandos tomó respecto de los resultados de la Crisis del canal de Suez, iban a marcar el destino de las álgidas dinámicas en las cuales se veía sometida la región, de una u otra forma Israel que tenía la preparación militar para combatir cualquier embate bélico de cualquier nación o conjunto de naciones de la región, pero tenía que reformar los principios diplomáticos bajo los cuales iba a respaldar el poderío económico que tenía sobre la región tomando una posición unilateral, cuando fuese necesario, o en su defecto apoyar las iniciativas estadounidenses, cuando esta opción se presente necesaria.

Por otro lado tanto Egipto, como Siria, vieron como el poderío militar de Israel era un peligro inminente y que si de alguna forma pretendían disputarle el dominio de la región tenían que tomar acciones en el intento de respaldar una posición militar respecto

\footnotetext{
${ }^{16}$ Peter L Hahn, "La Crisis de Suez: un suceso que cambió el equilibrio de poder en Oriente Medio" IIP/ Departamento de Estado de Estados Unidos, 23 de Septiembre de 2008.
} 
de los avances en términos diplomáticos que había significado la guerra, en ese sentido la cooperación militar fue cada vez más creciente, no sólo en recursos, sino en instrucción teórica y tecnológica.

\begin{tabular}{|c|c|c|c|c|}
\hline \multicolumn{5}{|l|}{ AYUDA } \\
\hline \multirow{2}{*}{\multicolumn{2}{|c|}{$\begin{array}{l}\quad \text { Economica } \\
\text { Poderes } \\
\text { occidentales (a) }\end{array}$}} & \multirow{3}{*}{$\frac{\begin{array}{l}\text { Bloque } \\
\text { soviético }(\mathrm{b})\end{array}}{1250}$} & \multicolumn{2}{|c|}{ Militar(c) } \\
\hline & & & $\begin{array}{l}\text { Poderes } \\
\text { occidentales }\end{array}$ & $\begin{array}{l}\text { Bloque } \\
\text { soviético }\end{array}$ \\
\hline Egipto (RAU) & 1650 & & 0 & $1500(d)$ \\
\hline $\operatorname{Irak}(e)$ & $75(c)$ & 220 & $150(\mathrm{f})$ & 400 \\
\hline Jordania & 100 & 0 & $450(\mathrm{~g})$ & 0 \\
\hline Líbano & $75(\mathrm{~h})$ & 0 & 25 (i) & 0 \\
\hline Siria & $135(j)$ & $200(k)$ & 0 & $350(1)$ \\
\hline Total Arabe & 2035 & 1670 & 625 & $2250^{\circ}$ \\
\hline Israel & $1500(\mathrm{~m})$ & 0 & $1000(\mathrm{n})$ & 0 \\
\hline $\begin{array}{l}\text { Total de la } \\
\text { zona }\end{array}$ & 3535 & 1670 & 1,625 & 2250 \\
\hline
\end{tabular}

a) Incluye créditos, donaciones y excedentes de venta de alimentos.

b) Crédito total ofrecido; porciones variables comprometidas hasta junio de 1965.

c) Incluye ventas, así como créditos y donaciones.

d) Se calcula $80 \%$ de la URSS, $20 \%$ de Checoslovaquia.

c) Casi todo de los Estados Unidos, antes de julio de 1958.

f) Se calcula más de $70 \%$ de la Gran Bretaña, y el resto de los EE.UU. (antes de julio de 1958).

g) Se calcula $85 \%$ de los EE.UU., $15 \%$ de la Gran Bretaña. La parte de los EE.UU. formalmente dada como ayuda al presupuesto, lo que permitió al gobierno jordano financiar sus fuerzas armadas.

h) Solamente de los EE.UU.

i) Se calcula $40 \%$ de Francia, 35\% de los EE.UU., 25\% de la Gran Bretaña.

j) Casi todo de los EE.UU.

k) $3 / 4$ de la URSS, el resto de Checoslovaquia y Polonia.

1) Se calcula $90 \%$ de la URSS y el resto de Checoslovaquia.

m) Se excluye remesas particulares y se calcula cerca de $40 \%$ de la Alemania Occidental y la mayor parte del resto de los EE.UU.

n) Se calcula $1 / 2$ de Francia, $1 / 5$ de la Alemania Occidental y el resto de Europa Occidental y de los EE.UU. A eso se debe agregar hasta $\$ 250$ millones o más en compra de excedente de armas que no es tán clasificados como ayuda.

\section{Imagen 1. Apoyo occidental y soviético a estados árabes de 1955 a 1965. ${ }^{17}$}

\section{La influencia soviética en las actuaciones y decisiones del panarabismo.}

Es innegable la influencia de la Unión Soviética sobre los movimientos nacionalistas que se dieron en el Oriente próximo, en ese orden de ideas, sería muy útil

\footnotetext{
${ }^{17}$ Z Schuldiner, “Las Relaciones Egipto-URSS”, Estudios Orientales 7, No. 3 (1972): 334.
} 
entender la lógica de estas relaciones y los factores por los cuales se llevaron a cabo, teniendo en cuenta antes que nada, el rol que tomó la Unión Soviética, como potencia, y el que tomaron las recién conformadas Repúblicas Árabes, según sus necesidades y problemáticas, siendo unas en términos ideológicos mucho más dogmáticas y otras mucho más pragmáticas, en el establecimiento y construcción de acuerdos y tratados con la Unión Soviética. Pero lo que si se debe asegurar es que tanto los acercamientos, del mundo árabe y la Unión Soviética, tienen perspectivas de corto o muy corto plazo, con la idea de obviamente solucionar problemáticas de atención inmediata.

Por el lado Soviético, era muy importante asegurarse aliados, dentro de sus espacios limítrofes, así como generar dinámicas de negociación indirecta respecto del petróleo, que existe en la región, pero el primer fin era primordial, teniendo en cuenta la transición entre la influencia anglo-francesa en la región y el interés norteamericano sobre la misma, era evitar un cercamiento estratégico, que de alguna forma se hacía evidente con los acercamientos de Grecia, Turquía y otros países de la región a la doctrina Truman, por el contrario, en ese sentido cabe aclarar que la Unión Soviética pasó por proceso de no agresión, con respecto a los Estados Unidos, de hecho después de la muerte de Stalin hubo un proceso de acercamiento de Jruchev, respecto de las potencias occidentales.

La situación de las recientes republicas árabes, era aún más inmediata en términos políticos y diplomáticos, persiguiendo antes que nada aceptación y respaldo en términos militares y económicos, ya que dentro de países como Egipto y Siria, quedaba mucho por consolidar y progresar después del ascenso al poder de las élites progresistas, en la década de 1950, en ese sentido, es muy importante para las crecientes republicas árabes, generar espacios de cooperación económica y política, con miras a hacer efectivo un proceso de modernización e industrialización de sus países.

\section{El caso egipcio}

El caso egipcio respecto desde su funcionamiento político fue consecuente con relación a la tesis de su filiación ideológica con doctrinas como el marxismo-leninismo, o el socialismo árabe, y la respuesta se puede encontrar en las actitudes estructurales del régimen en proporción a los interrogantes que le plantean, tanto la Unión soviética, como la facción comunista egipcia, y es que dentro del gobierno egipcio hubo ideales y fines preponderantes, como la consolidación de la revolución bajos unos ideales nacionales, y de ahí en más, la prevalencia y maniobrabilidad de las élites militares sobre los asuntos 
más importantes del país. Así mismo, es sabido que la revolución cobró "la plena dignidad como nación ante el aldabonazo invocador de sus gloriosas esencias históricas, con que han irrumpido en su historia un grupo de los más jóvenes y mejor preparados jefes y oficiales de su ejército, capitaneados por el presidente Nasser, que investido de un profundo sentido religioso de la vida, resulta hasta ridículo acusarle de convivencias con el marxismo ${ }^{18}$.

En ese sentido toda oposición fue sofocada y múltiples vínculos económicos, políticos y estratégicos fueron establecidos con potencias occidentales, en la función de modernizar el país, en ese sentido cabe recalcar que ni la propiedad privada, ni la participación de los capitales extranjeros, fueron abolidos dentro del mandato de Nasser, así mismo, es importante aseverar que es precisamente que en la flexibilidad respecto de las relaciones internacionales, era en que cabía el neutralismo de Nasser, sacando en cuestiones de ayudas económicas y financieras lo mejor de los dos mundos.

Ya que es innegable que la influencia económica de los Estados Unidos en la zona estaba marcada por la preeminencia técnica que siempre había poseído en relación a la extracción de crudo, respaldada en un vasto sector privado compuesto por múltiples compañías, sin las cuales era casi imposible la extracción de recursos petrolíferos, por lo menos no sin su ayuda. Sin embargo, los planteamientos diplomáticos estadounidenses en la región, se expresaban de forma profundamente neutral a razón de sus intereses por tales razones se referían así a la cuestión:

"mantener un elemento de equilibrio superficial en su postura pública, y tienen a veces desacuerdos con la política de Israel, [teniendo en cuenta que] el registro de nuestro apoyo es claro como el cristal. Esto nos ha costado mucho con los árabes, y dado que los soviéticos [plantean] una gran apertura para [con los mismos] y no tienen la intención de desviarse de esta política"19.

De ahí el giro en términos militares de Egipto y después de la RAU, tomando en consideración, la posición de los Estados Unidos respecto del patrocinio indirecto del Estado de Israel en términos armamentísticos, por medio de las potencias europeas, así como el respaldo y aceptación del mismo, lo cual se hace palpable en el siguiente intercambio de palabras de un diplomático norteamericano y Nasser:

\footnotetext{
${ }^{18}$ Marín Pérez, Lo Que vi En La R.A.U, 94.

19 /2/An undated briefing memorandum from Ball to Johnson on the Eshkol visit is ibid. Other briefing material is in the National Archives and Records Administration, RG 59, Conference Files: Lot 66 D 110 , CF 2406-2407. http://nasser.bibalex.org/Data/USDocWeb/HTML/XVIII-Arab-Israeli\%20Dispute-19641967/www.state.gov/www/about_state/history/vol_xviii/g.html\#61.Fecha de consulta: 28 de junio de 2016
} 
"En mayo de 1954 la Embajada en El Cairo informó de un notable incremento en la Federación de manifiestos en la actividad comercial, diplomática, cultural y frentes de propaganda. El actual embajador de Rusia llegó a Egipto en octubre de 1953. Él me dio las gracias por la información, pero en general daba la impresión no creía que nos encontraríamos capaces de hacerle comprar cantidades significativas de equipo de nosotros. Habló extensamente acerca de la aparente incapacidad de poderes tripartita para dejar [crecer] Egipto tan fuerte como a Israel. En este sentido, fue particularmente crítico de los franceses que [él] dice haber suministrado más grandes cantidades de tanques a Israel" 20 .

Fue ahí donde la ayuda y al influencia de la Unión soviética fue importante, teniendo en cuenta también las perspectivas de radicalización y de combate que aparecieron alrededor de la solución de la cuestión palestina y la preservación y cuidado de los recursos económicos de cada uno de los pueblos árabes, sin embargo lo primordial dentro de la coyuntura regional era que "las potencias occidentales ya no controlan exclusivamente los medios para mantener un equilibrio de armas entre los árabes y los israelíes. La nueva iniciativa soviética tenía serias implicaciones para (a) el conflicto árabe-israelí y (b) la influencia soviética en la zona"21.

Pero en términos generales los deseos estadounidenses nunca se movieron en pro de una disputa bélica, sino más bien del ascenso económico de la región basado en la intervención extranjera y en el predominio militar de Israel en la región, tomando una política de no intervención respecto a los pedidos militares de los aliados árabes que poseía en la región.

De ahí que la RAU recurriera a estrechar lazos diplomáticos con varios regímenes militares de la época, para consolidar vínculos y poder intercambiar ayuda técnica en términos armamentísticos e industriales a cambio de recursos petrolíferos y energéticos, en ese sentido, uno de los casos más documentados es el de la España franquista, donde los magníficos "saetas" de patentes españolas y construidos en una fábrica instalada en la R.A.U., en la que, desde el primer ingeniero hasta el más modesto de los obreros, eran españoles $^{22}$

\section{El caso sirio.}

20 Department of State, Central Files, 774.56/6-2155.'Secret. Drafted by Burdett. 0287. http://nasser.bibalex.org/Data/USDocWeb/PDF/Arab-Israeli-Dispute-1955-XIV/TXT/Arab-IsraeliDispute-1955-XIV\%20-\%200287.pdf.

${ }^{21}$ Department of State, S/S-NSC Files: Lot 63 D 351, NSC 5428 Memos (Nov.-Dec. 1955). Top Secret.0618. http://nasser.bibalex.org/Data/USDocWeb/PDF/Arab-Israeli-Dispute-1955-XIV/TXT/ArabIsraeli-Dispute-1955-XIV\%20-\%200618.pdf.

${ }^{22}$ Marín Pérez, Lo Que vi En La R.A.U, 73. 
En referencia al caso sirio, hay que tener en cuenta la naturaleza dogmática de su proceso de nacionalización a cargo del Baath, y es que este partido de calado socialista, fue la fuente teórica de los distintos movimientos nacionalistas de la región, por lo cual tiene una filiación más rígida, con relación a la posición que ocupa dentro del juego político que para la época detenta la Unión Soviética.

Bajo la égida de este partido se le dio vida al socialismo árabe, que contó con unas características muy particulares. Una de ellas fue que, gracias al poco desarrollo de los sectores productivos, como de las clases agrícolas y en especial de las obreras, tendió a no definirlas, ni categorizarlas, de esta forma respondió por una sociedad sin clases y una visión del socialismo sin estas. En términos culturales, también dio un vuelco respecto de la adhesión de las sociedades del Oriente Próximo, por lo que optó por un socialismo que reivindicaba lo árabe, y fue precisamente ahí donde radicó su éxito y su influencia en las perspectivas nacionalistas de las jóvenes repúblicas de la región, debido a su carácter flexible e interclasista, capaz de adaptarse a cualquier sistema económico y casi cualquier modo de gobierno.

La consolidación del Baath, dentro del ámbito sirio, se dio enfrentándose a la adherencia frente al Pacto de Bagdag, por medio de un movimiento de unidad nacional, representado por distintas visiones progresistas, socialistas y democráticas de la perspectiva nacional, gracias a su naturaleza ideológica concreta desarrolla vínculos con la Unión Soviética y es que la que la relación sirio-soviética se convirtió en un vínculo de total, permanente y mutua conveniencia, debido al carácter estratégico de Siria, que servía como tapón ante una hipotético cercamiento regional, ante los intereses y la posible preminencia de Estados Unidos sobre la región, así mismo, para Siria la cooperación económica, política, militar y estratégica fue vital en la función de hacer perdurable la República frente a las provocaciones de las que fue víctima Desde Bagdag mientras se desarrollaban las "conversaciones sirio-soviéticas destinadas a proveer de armamento a Siria y al estudio de una ayuda financiera y técnica para su desarrollo económico. Por esta vía entra el país, luego que en agosto la Unión Soviética le garantiza su integridad, y en octubre le concede importantes créditos ${ }^{23}$ De esta forma Siria, comparada con Egipto a pesar de su preponderancia dentro del mapa político de la región, poseyó un relación mucho más directa y duradera con la Unión Soviética, y gracias a ella ha sido un ente

\footnotetext{
${ }^{23}$ Couland, El Despertar Del Mundo Árabe, 88-89.
} 
mucho más estable y resistente a los embates y problemáticas que le plantea la dinámica internacional, principalmente en términos socio-económicos y militares.

\section{Conclusiones}

El nacimiento del Panarabismo, es gracias a la cristalización de relaciones diplomáticas flexibles y variables, tanto dentro del ámbito regional, como internacional, son precisamente estas, las de alguna forma truncaron y obstaculizaron su crecimiento, ya que la variabilidad y el carácter ambiguo de sus premisas, proyectos y fines políticos, hacen que en un periodo de dos o tres años, debido a la muerte de Nasser, las relaciones en referencia a la Unión Soviética y los Estados Unidos varíen de forma drástica. En ese sentido cabe recalcar que la protección y prevalencia de los intereses árabes-nacionales de determinadas entidades político-administrativas, pueden tomar múltiples orientaciones políticas.

Lo que de alguna forma se puede aseverar de los procesos nacionalistas árabes, fue su empeño por modernizar e industrializar los procesos productivos de los sectores económicos más atrasados, de ahí su aspiración a consolidar unas relaciones internacionales orientadas hacia la cooperación económica y financiera, teniendo en cuenta esta perspectiva, nunca se hicieron independientes o autónomas, en términos económicos, sino que se hicieron más dependientes de las ayudas, como del ejercicio diplomático para conseguirlas, terminando de las misma forma como empezaron, siendo ámbitos económicos enfocados en el funcionamiento de las instituciones financieras, la inversión y la importación de productos manufacturados, para dinamizar los pocos sectores económicos rentables, de unas economías dedicadas en su gran mayoría la producción de materias primas.

Lastimosamente la premisa sobre la cual se dio el desarrollo del panarabismo como corriente política, no se consolidó demasiado y es que la prevalencia de las clases obreras y agrícolas, junto con los ideales progresistas se quedó en las transformaciones teóricas y retóricas de los partidos políticos llenos de juventud y brío, convirtiéndose en su llegada al poder en gobiernos de calado militarista, profundamente preocupados por las relaciones diplomáticas, así como por la centralización y concentración de las actividades gubernamentales, las riquezas y los recursos. Y es que la resolución de las perspectivas y problemáticas de las clases trabajadoras quedaron pendientes, gracias al 
TEMPUS Revista en Historia General

incompleto desarrollo industrial y a la dependencia económica, a pesar de que hubo una intención tanto teórica como práctica de mejorar la situación social de las clases trabajadoras.

\section{FUENTES}

Documentación de US Departamento de Estado tomada de: http://www.nasser.org/home/main.aspx?lang=en

\section{BIBLIOGRAFÍA}

ABDEL-MALEK, Anouar. "El Islam político." Revista Mexicana de Sociología 41, no. 3 (Jul. - Sep., 1979): 909-923.

AJAMI, Fouad. "Los pesares de Egipto." Política Exterior 10, no. 49 (1996): 93-109.

BELTRÁN, Virgilio Rafael. "Las Fuerzas Armadas como élite modernizante en algunas sociedades en transición del Medio Oriente." Desarrollo Económico 4, no. 13 (1964): 4968.

COULAND, Jacques. El Despertar Del Mundo Árabe. Buenos Aires: Arandú, 1965.

DAVIDI, Efraim. "La crisis del Canal de Suez en 1956: El fin de una época en el Medio Oriente y el comienzo de otra." Historia Actual Online, no. 10 (primavera, 2006): 145153.

GIRALDO Herrera, Paola. Gamal Abdel Nasser : El Faraón Rojo. Panamericana, 2005.

GARCÍA de las Heras González, Mariano, "El Egipto de Nasser en la dinámica de las Relaciones Internacionales", $A b$ Initio, no. 1 (2010): 149-168, http://www.abinitio.es/wp-content/uploads/2013/03/Ab-Initio-I-ART07-El-Egipto-de-Nasser.pdf Fecha de consulta: 9 de octubre de 2015

HAHN, Peter L. "La crisis de Suez: Un suceso que cambió el equilibro de poder en Oriente Medio" IIP/ Departamento de Estado de Estados Unidos, 23 de Septiembre de 2008.

MARÍN Pérez, Pascual. Lo que vi en la R.A.U. Madrid: Embajada de la República Árabe Unida, 1966.

PAPPE, Ilan. Historia de la Palestina Moderna. Madrid: Akal. 2007.

PLUN Louise, «Michel Aflaq et Salah al-Bitar: idéologues et fondateurs du parti Ba'th, 》 Fecha de consulta: 9 de octubre, 2015. http://www.lesclesdumoyenorient.com/Michel-Aflaq-et-Salah-al-Bitar.html\#nh7

SAID, Edward W. Orientalismo. Barcelona: Debate. 2013.

SAINT-PROT, Charles. Le Mouvement National Arabe, emergence et maturation du Nationalisme Arabe de la Nahda au Baas. París: Ellipses. 2013.

SCHULDINER, Zvi. "Las Relaciones Egipto-URSS." Estudios Orientales 7, no. 3 (1972): 294-334. 
TIXIER, Gilbert. "La Unión de las Repúblicas Árabes y la Constitución Egipcia de 11 de Septiembre de 1971." Revista de Estudios Políticos, no. 185 (Septiembre/Octubre 1972): 251-260. 